\title{
A comparative study of fracture shaft of femur in adults treated with broad dynamic compression plate versus intramedullary interlocking nail
}

\author{
Sushil Thapa ${ }^{1}$, Shrawan Kumar Thapa ${ }^{1}$, Shankar Dhakal ${ }^{1}$, Rudra Marasini ${ }^{1}$, Bhadra Hamal ${ }^{2}$, Rem \\ Kumar Rai ${ }^{2}$, Rahul Shrestha ${ }^{3}$, Manoj Kandel ${ }^{1}$ \\ ${ }^{1}$ Department of Orthopaedics, Bharatpur Hospital, Bharatpur, Chitwan \\ ${ }^{2}$ Department of Orthopedics, NAMS, Kathmandu \\ ${ }^{3}$ Department of Orthopedics, College of Medical Sciences, Bharatpur, Chitwan
}

\section{Correspondence \\ Dr. Sushil Thapa \\ Department of Orthopaedics \\ Bharatpur Hospital \\ Bharatpur, Chitwan, Nepal \\ Email: talktosus@gmail.com}

DOI: http://dx.doi.org/10.3126/ jemsn.v12i2.15453

Article received: March $15^{\text {th }} 2016$ Article accepted: June $20^{\text {th }} 2016$

\begin{abstract}
Background \& Objectives: Diaphyseal femur fracture is one of the commonest fractures to present in an emergency room. The objective of the study was to compare femoral shaft fractures treated using nail with those using plate and screws. Materials \& Methods: We studied a total of 62 patients of fracture shaft of femur admitted in the Bharatpur Hospital, Bharatpur, Chitwan and National Academy of Medical Sciences, Bir Hospital, Kathmandu. Two cases were lost to follow up. Thirty cases were treated with plating and 30 cases with nailing. The age group was from 16-30 years. Fifty-three were male and seven were females. Fiftyeight patients had closed fracture and two had Gustillo Anderson grade I open fracture. Results: Time from injury to surgery was 19 days on an average. Mean time for union was more in patients treated by plating, 19.46 weeks as compared to nailing 14.78 weeks. We found one case of infection with plating and breakage of plate in four patients. One patient with nailing did not show any signs of healing and two had failure in case of nailing. Our series revealed $23(38.3 \%)$ excellent, five $(8.3 \%)$ good and two $(3.3 \%)$ poor results in patients who had nailing while $15(25.5 \%)$ excellent, nine $(15 \%)$ good, one $(1.7 \%)$ fair and five $(8.3 \%)$ poor in patients who had plating out of 30 patients in each group. Conclusion: In our study we found that there was no significant difference in outcomes between plating and intramedullary nailing of femoral diaphysis fracture in terms of union, infection and implant failure.

Key words: Femoral plating; femoral shaft fracture; intramedullary interlocking nail; Thorensen criteria
\end{abstract}

Citation: Thapa S, Thapa SK, Dhakal S, Marasini R, Hamal B, Rai RK, Shrestha R, Kandel M. A comparative study of fracture shaft of femur in adults treated with broad dynamic compression plate versus intramedullary interlocking nail. JCMS Nepal. 2016;12(2):66-9.

\section{INTRODUCTION}

Fracture shaft of femur is one of the most common fractures seen in orthopaedic practice. ${ }^{1}$ Femur is the longest bone of the body and one of the principal load bearing bones in the lower extremity. ${ }^{2}$ Fracture of femoral shaft, often, is the result of high energy trauma like motor vehicle accidents, fall from height, automobile pedestrian accident, and gunshot injury and may be associated with multiple system injury. ${ }^{3}$ Because of high morbidity and mortality in fracture shaft of femur, early evaluation and choosing specific management is highly recommended. ${ }^{4}$ The treatment of femoral shaft fracture has evolved from the historical nonoperative management to the most recent operative method. Several techniques are available for the treatment of fracture shaft of femur. ${ }^{5}$ Closed reduction, spica cast immobilization, skeletal traction, femoral cast bracing, external fixation, internal fixation with plating, un-reamed/reamed intramedullary interlocking nail are some of the treatment modalities available to us. ${ }^{5}$ Surgeon should be capable of using all these technique and must weigh advantages and disadvantages of each one and adapt best positive treatment. The best treatment should be determined by a thoughtful analysis of morphology of the fracture, the mechanical characteristics of the bone, general condition of the patient and most importantly the status of tissues (the skin, muscle associated with 
neurologic and vascular status of leg). ${ }^{5}$

The purpose of this study is to compare the outcome of nailing with that of plating in terms of several variables.

\section{MATERIALS AND METHODS}

This study was a comparative study conducted in Bharatpur Hospital, Bharatpur and National Academy of Medical Sciences, Bir Hospital from 2013 February to 2015 February. The children of age more than 18 years with diaphyseal fracture amenable to operative fixation with intramedullary nail and plate were included. The exclusion criteria included those with an evidence of infection during surgery, pathological fracture, those unwilling to go surgery. The sample size was 30 cases in each group. The patients were randomized alternately into intramedullary nailing and plating groups. The details of each patient and the values of each variable were filled up in Statistical Package for the Social Sciences (SPSS) software version 22. After the data of all sixty patients were filled up, the standard deviation and $p$ value of different variables were calculated. The outcome was compared using the Thorensen criteria ${ }^{6}$ as presented in table 1.

\section{RESULTS}

In this study, out of 30 patients in nailing group, 20 $(33.3 \%)$ patients were in the age group of 16 to 30 years and $10(16.07 \%)$ patients were in the age group of 31 to 50 years while out of 30 patients in plating group, $18(30 \%)$ were in the age group of 18 to 30 years, nine $(5 \%)$ patients were 31 to 50 years. The difference was statistically insignificant ( $p$ value 0.206).

\section{Pain and swelling at 24 weeks}

At 24 weeks, pain and swelling was absent in 25 $(41.7 \%)$ patients, minor or sporadic in three $(5 \%)$ patients and severe in two $(3.3 \%)$ patients of nailing group and absent in $13(21.7 \%)$ patients, minor or sporadic in $12(20 \%)$ patients, significant in one $(1.7 \%)$ patient and severe in four $(6.7 \%)$ patients of plating group. The difference was statistically insignificant ( $p$ value $=0.013$ )

\section{Limb length discrepancy at 24 weeks}

Leg length discrepancy in nailing patients was $<1 \mathrm{~cm}$ in 24 patients $(40 \%)$ and $<2 \mathrm{~cm}$ in six patients $(10 \%)$ while in plating group was $<1$ $\mathrm{cm}$ in 15 patients $(25 \%),<2 \mathrm{~cm}$ in 10 patients $(16.7 \%),<3 \mathrm{~cm}$ in one patient $(1.7 \%)$ and $<4$ $\mathrm{cm}$ in four patients $(6.7 \%)$ at the end of 24 weeks. The difference was statistically insignificant ( $p$ value $=0.044$ )

\section{Varus/valgus malalignment}

Varus/valgus malalignment was $<5$ degrees in 28 (46.7\%) nailing patients and $16(26.7 \%)$ plating patients and five degree in $10(16.7 \%)$ patients with plating and $>10$ degrees in two (3.3\%) nailing patients and four $(6.7 \%)$ plating patients. The difference was statistically significant (p value $=0.0010$ ).

\section{Flexion of knee at 24 weeks}

At 24 weeks, flexion of knee joint in nailing patients was more than 120 degrees in $25(41.7 \%)$ patients with nailing and $15(25 \%)$ cases with plating, 120 degrees in three $(5 \%)$ patients with nailing and $10(16.7 \%)$ patients with plating and 90 degrees in two (3.3\%)patients with nailing and five $(8.3 \%)$ patients with plating. The difference was statistically insignificant ( $\mathrm{p}$ value $=0.023$ ).

\section{Extension of knee at 24 weeks}

Extension deficit of knee at 24 weeks was five degrees in $25(41.7 \%)$ nailing patients and $15(25 \%)$ plating patients, 10 degrees in three $(5 \%)$ nailing and $11(18.3 \%)$ plating patients and 15 degrees in two $(3.3 \%)$ nailing and four $(6.7 \%)$ plating patients. The difference was statistically insignificant $(p$ value $=0.021$ )

\section{Internal rotation}

Out of 30 patients in nailing group, internal rotation was five degrees in $28(46.7 \%)$ patients, and $>15$ degrees in two patients $(3.3 \%)$. While in plating group it was five degrees in $15(25 \%)$ patients, 10 degrees in $11(18.3 \%)$ patients and 15 degrees in

Table 1: Thorensen criteria

\begin{tabular}{|c|c|c|c|c|}
\hline & \multicolumn{4}{|c|}{ Results } \\
\hline & $\begin{array}{l}\text { Excelle } \\
\text { nt }\end{array}$ & Good & Fair & Poor \\
\hline Pain/Swelling & None & $\begin{array}{l}\text { Sporadi } \\
\text { c/Minor }\end{array}$ & $\begin{array}{l}\text { Signifi } \\
\text { cant }\end{array}$ & Severe \\
\hline \multicolumn{5}{|l|}{$\begin{array}{l}\text { Malalignment of } \\
\text { femur (degrees) }\end{array}$} \\
\hline Varus/Valgus & $<5$ deg & $5 \mathrm{deg}$ & $10 \mathrm{deg}$ & $>10 \mathrm{deg}$ \\
\hline Internal rotation & $5 \mathrm{deg}$ & $10 \mathrm{deg}$ & $15 \mathrm{deg}$ & $>15 \mathrm{deg}$ \\
\hline External rotation & $10 \mathrm{deg}$ & $15 \mathrm{deg}$ & $20 \mathrm{deg}$ & $>20 \mathrm{deg}$ \\
\hline $\begin{array}{l}\text { Antecurvatum/ } \\
\text { Rercurvatum }\end{array}$ & $<5 \mathrm{deg}$ & $5 \mathrm{deg}$ & $15 \mathrm{deg}$ & $>15 \mathrm{deg}$ \\
\hline $\begin{array}{l}\text { Shortening of } \\
\text { Femur(cm) }\end{array}$ & $<1$ & $<2$ & $<3$ & $<4$ \\
\hline \multicolumn{5}{|l|}{$\begin{array}{l}\text { Range of Motion } \\
\text { (Degree) }\end{array}$} \\
\hline Flexion & $\begin{array}{l}>120 \\
\operatorname{deg}\end{array}$ & $120 \mathrm{deg}$ & $90 \mathrm{deg}$ & $<90$ deg \\
\hline Extension deficit & $5 \mathrm{deg}$ & $10 \mathrm{deg}$ & $15 \mathrm{deg}$ & $>15 \mathrm{deg}$ \\
\hline
\end{tabular}


four $(6.7 \%)$ patients at the end of 24 weeks. The difference was statistically significant ( $\mathrm{p}$ value $=0$ )

\section{DISCUSSION}

In this study, 60 cases of fracture of shaft of femur were studied. Out of them, 30 were treated with intramedullary nailing and the other 30 with plating. Out of them, twenty-three nailing and fifteen plating cases showed excellent result while five nailing and nine plating showed good results. Only one plating case showed fair result while two nailing and two plating cases showed poor results as shown in the table 2. Clinical evaluation of the outcome was assessed at 24th week follow up visit using Thorensen et $\mathrm{al}^{6}$ criteria and radiological data were evaluated.

Stannard et $\mathrm{al}^{7}$ performed nailing on fifty-four patients. Out of them $41 \%$ had pain and swelling over the fracture site. In our study, $10 \%$ of the patients who underwent nailing complained of pain and swelling over the fracture site. In our study, the incidence of pain and swelling was significantly less than that in the former study. The reduced incidence of pain and swelling could be due to administration of analgesics and anti-inflammatory drugs round-the-clock for five days.

Thorensen et $\mathrm{al}^{6}$ performed nailing in 48 patients. The average malalignment in them was less than ten degrees. Out of 30 patients in our study, the average malalignment was less than five degrees. The average malalignment after nailing in our study is comparable to that in Thorensen et al's study. ${ }^{6}$ That is because in nailing perfect anatomical reduction is difficult to achieve in both closed or open technique.

Apivatthakaul et $\mathrm{al}^{8}$ carried out plating in 34 patients. The average varus/valgus malalignment in them was less than ten degrees. In our patients who underwent plating, the average varus/valgus malalignment was less than five degrees. The average varus/valgus malalignment after plating in our study is also comparable to the former study. The degree of malalignment in plating was less in our study because reduction was done under direct

Table 2: Final result

\begin{tabular}{llll} 
Result & Nailing & Plating & Total \\
Excellent & 23 & 15 & 38 \\
Good & 5 & 9 & 14 \\
Fair & 0 & 1 & 1 \\
Poor & 2 & 5 & 7 \\
Total & 30 & 30 & 60 \\
\hline
\end{tabular}

vision.

Ilangovan ${ }^{9}$ studied the final range of motion in twenty patients who underwent nailing. The range of flexion was 0 to 120 degrees. In our study in 30 patients, who underwent nailing, the final range of motion was 0 to 120 degrees. Out of fifty patients on whom Broos et $\mathrm{al}^{10}$ performed plating, the range of flexion was 0 to 90 degrees. In our thirty such patients the final range of motion was 5 to 120 degrees. The outcome of our study in terms of the range of motion is equally good as compared to Ilangovan's study. This was the result of extensive physiotherapy in our patients after surgery.

Moumni et $\mathrm{al}^{11}$ studied the outcome in terms of extension deficit in 79 patients who underwent nailing. It was more than five degrees. In our study on whom fracture was fixed with nailing in thirty patients, the average extension deficit was less than five degrees. But the extension deficit in those with plating was more than five degrees. This was because during surgical approach in plating, the extensor mechanism was affected. Hufner et al ${ }^{12}$ studied the outcome of nailing in 89 patients. The average loss of internal rotation was more than 15 degrees and that in ours ( 30 patients) was five degrees. Rozbruch et $\mathrm{al}^{13}$ studied the outcome of plating in 81 patients. The average loss of internal rotation was more than 15 degrees and that in ours was more than five degrees. The functional outcome of nailing of femoral fractures is better than that in Moumni et $\mathrm{al}^{11}$ and Rozbruch et al's ${ }^{13}$ study. The outcome of plating in our study is comparable to that in Moumni et al. ${ }^{11}$

\section{CONCLUSION}

In our study we didn't find incidence of pulmonary embolism, deep venous thrombosis or mortality in the cases treated with either plate or nail. The outcome of nailing was comparable with that of plating in terms of various complications. The functional outcome of plating and nailing in terms of several variables like varus/valgus malalignment, extension deficit, range of motion and loss of internal rotation was comparable. So in this study, there is no statistical difference in outcome of dynamic compression plating and that of intramedullary interlocking nailing in case of fracture of diaphysis of adult femur.

\section{REFERENCES}

1. Ali MA, Hussain SA, Khan MS. Evaluation of results of interlocking nails in femur fractures due to high velocity gunshot injuries. J Ayub Med Coll Abbottabad. 2008;20 
(1):16-9. PMID:19024178.

2. Kimmatkar N, Hemnani JT, Hemnani T, Jain S. Diaphyseal femoral intramedullary nailing: closed or open intervention. International Journal of Scientifi c Study. 2014;1(5):15-8.

3. Afsar SS, Gulzar M, Babar IU. A one year review of various complications in fracture shaft of femur managed with closed intramedullary interlocking nail. Journal of Postgraduate Medical Institute (Peshawar-Pakistan). 2013;27(3):336-41.

4. Mirza A, Ellis T. Initial management of pelvic and femoral fractures in the multiply injured patient. Critical care clinics. 2004;20(1):159-70. DOI: 10.1016/S0749-0704(03) 00096-4.

5. Naeem-Ur-Razaq M, Qasim M, Khan MA, Sahibzada AS, Sultan S. Management Outcome OF Closed Femoral Shaft Fractures by Open Surgical Implant Generation Network (SIGN) Interlucking Nails. J Ayub Med Coll Abbottabad. 2009;21(1):21-4. PMID:20364733.

6. Thoresen B, Alho A, Ekeland A, Strømsøe K, Follerås G, Haukebø A. Interlocking intramedullary nailing in femoral shaft fractures. A report of forty-eight cases. JBJS Case Connector. 1985(9):1313-20.

7. Stannard JP, Bankston L, Futch LA, McGwin G, Volgas DA. Functional outcome following intramedullary nailing of the femur. The Journal of Bone \& Joint Surgery. 2011;93(15):1385-91.

8. Apivatthakakul T, Chiewcharntanakit S. Minimally invasive plate osteosynthesis (MIPO) in the treatment of the femoral shaft fracture where intramedullary nailing is not indicated. International orthopaedics. 2009;33(4):111926. DOI: 10.1007/s00264-008-0603-2. PMID:18597087.

9. SP I. Role of Intramedullary Interlocking Nailing in Complex Femoral Shaft fractures IOSR Journal of Dental and Medical Sciences. 2014;13(5):51-6.

10. Broos P, Sermon A. From unstable internal fixation to biological osteosynthesis. A historical overview of operative fracture treatment. Acta chirurgica Belgica. 2004; (4):396-400. PMID:15469150.

11. Moumni ME VE, Duis H, Wendt KW. Long-term functional outcome following intramedullary nailing of femoral shaft fractures. Int J Care Injured. 2012;43(7):1154 -8. DOI: 10.1016/j.injury.2012.03.011. PMID:22483542.

12. Hüfner T, Citak M, Suero EM, Miller B, Kendoff D, Krettek C, et al. Femoral malrotation after unreamed intramedullary nailing: an evaluation of influencing operative factors. Journal of orthopaedic trauma. 2011;25 (4):224-7. DOI: 10.1097/BOT.0b013e3181e47e3b. PMID:21399472.

13. Rozbruch RS, Müller U, Gautier E, Ganz R. The evolution of femoral shaft plating technique. Clinical orthopaedics and related research. 1998;354:195-208. DOI:

10.1097/00003086-199809000-00024. PMID:9755780. 